\title{
Mixed dementia
}

\section{A review of the evidence}

\author{
Nilton Custodio ${ }^{1,2}$, Rosa Montesinos ${ }^{1,3}$, David Lira ${ }^{1,2}$, Eder Herrera-Pérez ${ }^{1,4,5}$ \\ Yadira Bardales ${ }^{1,6}$, Lucía Valeriano-Lorenzo $0^{1,7}$
}

\begin{abstract}
Mixed dementia is the coexistence of Alzheimer's disease and cerebrovascular disease (CVD) in the same demented patient. Currently, its diagnosis and treatment remains a challenge for practitioners. To provide an overview of the epidemiology, pathogenesis, natural history, diagnosis, and therapy of Mixed Vascular-Alzheimer Dementia (MVAD). The literature was reviewed for articles published between 1990-2016 by using the keywords linked to MVAD. Neuropathological studies indicate that MVAD is a very common pathological finding in the elderly with a prevalence about of $22 \%$. The distinction between Alzheimer's dementia and vascular dementia (VD) is complex because their clinical presentation can overlap. There are international criteria for the MVAD diagnosis. The pharmacologic therapy shows modest clinical benefits that are similar among all drugs used in patients with Alzheimer's dementia and VD. The nonpharmacologic therapy includes the rigorous management of cardiovascular risk factors (especially hypertension) and the promotion of a healthy diet. The diagnosis and treatment of MVAD cannot be improved without further studies. Currently available medications provide only modest clinical benefits once a patient has developed MVAD. In subjects at risk, the antihypertensive therapy and healthy diet should be recommend for preventing or slowing the progression of MVAD.
\end{abstract}

Key words: mixed dementia, Alzheimer's disease, vascular dementia, cerebrovascular disease.

\section{DEMÊNCIA MISTA: REVISÃO DAS EVIDÊNCIAS}

RESUMO. Demência mista é denominação usual para a coexistência da doença de Alzheimer e doença cerebrovascular (DCV) no mesmo paciente demente. Atualmente, seu diagnóstico e tratamento continuam sendo um desafio. Fornecer uma visão geral da epidemiologia, patogênese, história natural, diagnóstico e terapia da Demência Mista AlzheimerVascular (DMAV). Foi realizada revisão da literatura buscando por artigos publicados entre 1990 e 2016 usando palavraschave relacionadas ao DMAV. Estudos neuropatológicos indicam que DMAV é um achado patológico muito comum em idosos, com uma prevalência de cerca de 22\%. A distinção entre demência de Alzheimer e demência vascular (DV) é complexa porque suas apresentações clínicas podem se sobrepor. Existem critérios internacionais para o diagnóstico DMAV. A terapia farmacológica mostra benefícios clínicos modestos que são semelhantes para todos os medicamentos utilizados em pacientes com demência de Alzheimer e DV. A terapia não-farmacológica inclui o manejo rigoroso dos fatores de risco cardiovascular (especialmente a hipertensão) e a promoção de uma dieta saudável. 0 diagnóstico e 0 tratamento do DMAV não podem ser melhorados sem outros estudos. Os medicamentos atualmente disponíveis fornecem apenas benefícios clínicos modestos, depois que DMAV instalou-se. Em indivíduos em risco, a terapia anti-hipertensiva e uma dieta saudável devem ser recomendadas para prevenir ou retardar a progressão da DMAV.

Palavras-chave: demência mista, doença de Alzheimer, demência vascular, doença cerebrovascular.

\section{INTRODUCTION}

ccording to the American Heart AssociaAtion/American Stroke Association (AHA/ ASA), the vascular and neurodegenerative disorders are common in the elderly and it could coexist in the same patient. These processes underlying dementia are mutually potentiated for developing cognitive impairment and dementia, generating overlapped clinical phenotypes and neuroimaging. ${ }^{1}$ Thus, the mixed

This study was conducted at the Unidad de Diagnóstico de Deterioro Cognitivo y Prevención de Demencia. Instituto Peruano de Neurociencias. Lima, Perú.

Unidad de Diagnóstico de Deterioro Cognitivo y Prevención de Demencia. Instituto Peruano de Neurociencias. Lima, Perú. Servicio de Neurología. Instituto Peruano

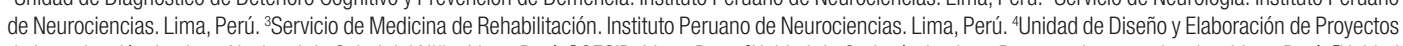

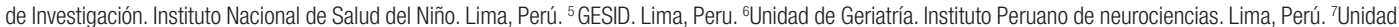
de Neuropsicología. Instituto Peruano de Neurociencias. Lima. Perú.

Nilton Custodio. Instituto Peruano de Neurociencias - Bartolomé Herrera 161, Lince - Lima - Peru. E-mail: ncustodio@ipn.pe

Disclosure: The authors report no conflicts of interest.

Received: September 16, 2017. Accepted in final form November 16, 2017. 
dementia occurs in patients with a neurodegenerative disorder (such as Alzheimer's disease (AD), Lewy body disease, or Pick body disease) and, additionally, a cerebrovascular disease (CVD). ${ }^{2}$

The mixed dementia, the Alzheimer's dementia, and the vascular dementia (VD) are the most frequent types of dementia, ${ }^{3}$ which could be related to each other. There is evidence of the near linkage between $A D$ and the CVD. For example, CVD lesions such as lacunes and white matter lesions (WML), are common in patients with $\mathrm{AD}$. Likewise, typical pathological changes of $\mathrm{AD}$, as extracellular amyloid plaques ("senile senile") and intracellular neurofibrillary tangles (NFT), are observed in elderly patients with VD. ${ }^{4}$ Finally, the brain lesions of AD and VD often occur together ${ }^{5-7}$ and interact in several ways to increase the likelihood of clinically significant cognitive decline. ${ }^{8,9}$

For an optimal treatment of dementia, the adequate diagnosis of each dementia type is essential. However, recognizing the distinction between these diseases can be difficult in clinical practice. This review provides an overview of the Mixed Vascular-Alzheimer Dementia (MVAD, addressing the epidemiological, pathogenic, clinical, diagnostic and therapeutic aspects of this medical condition.

\section{METHODS}

Search strategy. Studies published between 1990 and 2016 were obtained from the following databases: Medline, Biomed Central, Embase, Scopus, Scirus, PsychInFO, LILACS and IBECS. Scholar Google, Ovid, Ebsco, Proquest, Cochrane Library, Cochrane Library Plus and WHO/PAHO databases was reviewed too. All languages were considered. The authors independently searched in specific fields (title, abstract and, if available, subject) for the following terms: (Dementia) AND ("Alzheimer Disease") AND ("Cerebrovascular Disorders" OR "Brain Ischemia" OR "Carotid Artery Diseases" OR "Cerebral Small Vessel Diseases" OR "Cerebrovascular Trauma" OR "Intracranial Arterial Diseases" OR "Intracranial Arteriovenous Malformations" OR "Intracranial Embolism and Thrombosis" OR "Intracranial Hemorrhages" OR "Stroke" OR "Central Nervous System Vasculitis"). Abstracts of articles in any language were independently reviewed by the authors. The only inclusion criterion was that the study should be available as full text in any bibliographic or academic databases. We did secondary search of reference lists of identified studies and received additional references frominternational experts. Thelatest date of publication for inclusion of articles in the study was 31 ${ }^{\text {th }}$ July 2017.
Ethics. No approval from the ethics committee was required since the study was carried out solely with published data from the world literature.

\section{EVIDENCE SYNTHESIS}

Selection of studies. In the consulted databases our search strategy identified 357 scientific documents (original articles, reviews and conference papers), which 26 articles addressed the topic of "mixed dementia" and 8 key articles were selected for this study, including a previous review about mixed dementia. ${ }^{10}$ Additional references were selected through of expert suggestions (3 articles) and secondary search of the mentioned documents. Finally, the total of references of this study were completed according the required information for each section (epidemiology, pathogenesis, etc.).

Epidemiology. Several autopsy-based studies reported a dementia prevalence of $39.5 \%-44.4 \%,{ }^{11-13}$ corresponding $36 \%-50 \%$ to Alzheimer's dementia, ${ }^{12-15}$ $30 \%-43.0 \%$ to DV, ${ }^{11,13,14}$ and $20 \%-22 \%$ to MVAD. ${ }^{13,16}$ Other studies have found that $5 \%,{ }^{14} 28 \%{ }^{17}$ and $35 \%{ }^{15}$ of the demented subject's autopsies had mixed lesions of CVD-AD. Communities based studies have showed a dementia prevalence of $12.4 \%$ (73/590), with a proportion of CVD lesions of $67.1 \%$. In this study the prevalence of MVAD and AD with CVD were $1.7 \%$ and $4.7 \%$, respectively. ${ }^{18}$

Other autopsy-based studies showed that the dementia proportion increases from $57 \%$ to $75 \%$ due to the presence of large artery infarctions and up to $93 \%$ due to the presence of lacunar infarcts. ${ }^{19}$ Likewise, the presence of single and multiple infarctions multiplies the dementia risk by 2.12 and 2.67 times, respectively. In autopsies with few neuritic plaques (mature plaques or amyloid plaques) Petrovitch et al. demonstrated that the synergistic effect of CVD-AD through finding a very high proportion of dementia among those with coexisting vascular lesions. ${ }^{20}$

Pathogenesis. The MVAD, as well as other dementias, starts several years before the symptoms display, which allow their diagnosis. ${ }^{21,22}$ The pathogenesis of Alzheimer's dementia is unclear. However, there are two theories that attempt to explain their origin: amyloid theory and vascular theory. Taking into account the theme of this review, we consider pertinent to discuss the last theory.

According to vascular theory, the chronic noncommunicable diseases (hypertension, diabetes mellitus, dyslipidemia, obesity, and cardiac disease) and the sedentary lifestyle produce several vascular changes ${ }^{23,24}$ 
such as the thickening of the capillary basal membrane and the accumulation of collagen in the vascular endothelium, which both generate vascular atrophy of the vascular terminations, as well as a decrease in the number of terminal blood vessels. These changes affect the cerebral microvasculature and reduces the cerebral blood flow, ${ }^{9,25}$ which especially observed in untreated hypertensive patients and those treated irregularly or insufficiently. ${ }^{26}$

There have been reports of different mechanisms of vascular damage such as small vessel atherosclerosis, large vessel arteriosclerosis, cortical and subcortical infarcts, lacunar infacts with gray/white matter lesions, WML (leukoaraoisis), demyelination, gliosis, amyloid angiopathy, and small brain hemorrhages. ${ }^{3,27,28}$ All these damages would progressively accumulate it, producing hypoperfusion, neuronal death and cerebral atrophy, and accumulating beta-amyloid and phosphorylated tau proteins. Considering that neurovascular dysfunction seems to play a key role in the pathogenesis of $A D$, some researchers have suggested that $A D$ is a primary vascular-cerebral disorder..$^{29,30}$

According several epidemiological studies, the main vascular risk factors are the age, ${ }^{31}$ hypertension, ${ }^{32,33}$ hyperhomocysteinemia, ${ }^{34,35}$ and WML that are shown as hyperintensities (hypersignals) in brain magnetic resonances. ${ }^{36,37}$ The presence of these factors increases the injury risk to the cerebral blood vessels, leading to CVD, which can progress to cerebral vascular injury (CVI), whether large or small arteries. With the CVD establishment can emerge manifestations of cognitive deficits that exceed those of normal aging, classified as vascular cognitive impairment (VCI), and progressing to affect daily living activities and social/occupational functioning, i.e. VD. ${ }^{2-4}$

In the case of $\mathrm{AD}$, some studies reported a set of brain changes during the presymptomatic phase, which includes accumulation of beta-amyloid protein, tau protein and phosphorylated tau protein, alterated glucose metabolism, ${ }^{38-40}$ and cortical thinning ${ }^{41}$ and cortical atrophy, ${ }^{42}$ which occurs 10 years before the onset of symptoms. All these changes have a deleterious and irreversible effect on the brain, and accumulate over time until triggering the clinical manifestations.

\section{Diagnosis}

Clinical diagnosis. There is no consensus for the diagnosis of MVAD. Thus, international referents such as the Alzheimer's Disease Diagnostic and Treatment Centers $(\text { ADDTC })^{43}$ and the National Institute of Neurological Disorders and Stroke and Association Internationale pour la Recherche et l'Enseignement en Neurosciences (NINDS-AIREN) $^{44}$ have proposed diagnostic criteria that differ from each other. A third organization, the Consortium to Establish a Registry for Alzheimer's Disease (CERAD), has not considered MVAD in its classification system. ${ }^{45}$

According to the ADDTC criteria, the diagnosis of MVAD requires the existence of a typical $A D$ and closely dementia related CVD. ${ }^{43}$ The NINDS-AIRRN criteria include evidence of: 1 ) memory compromise and $\geq 2$ other cognitive areas; 2) CVI (focal neurological signs and detection of WML in brain images); and 3) dementia onset during the first 3 months after the cerebral stroke. ${ }^{44}$

Additionally, we recommend an approach aimed to identify the dominant component (CVI or AD). Thus, in the majority of patients with predominance of CVI lesions, the initial clinical phenotype should be as VD (i.e., impairment in frontal-executive functions, rather than memory), ${ }^{46}$ with a later deterioration of attention/ concentration. ${ }^{47}$ Otherwise, in patients with predominance of $\mathrm{AD}$, the initial clinical phenotype is episodic memory impairment, with a progressively addition of sub-cortical dementia and a step-by-step evolution of disease (which differs with the typical gradual evaluation of the AD). ${ }^{48,49}$

Neuroimaging. The neuroimaging studies is useful for increasing the diagnostic certainty, particularly in silent lesions such as lacunar infarcts and WML. ${ }^{47,50}$ However, there are not pathognomonic imaging signs of VCI/VD and the findings should be interpreted based on individual clinical context. According the VASCOG statement, a near temporal relationship between vascular event and the cognitive symptoms/signs must be present to suspect VCI/VD (ideally, 3 months), especially if previous imaging has been undertaken. ${ }^{47,51}$

Pathologic diagnosis. A definitive diagnosis warrants a neuropathologic verification. Regarding the clinicalpathological diagnosis of MVAD, we suggest to use the recommendations for the $\mathrm{AD}$ diagnosis based on morphological changes (Table 1). ${ }^{52}$ According to the guides of the National Institute of Aging (NIA) and the Ronald and Nancy Reagan Institute from the Alzheimer's Association, the postmortem diagnosis of AD can be performed by combining the criteria of CERAD and Braak NFT staging. ${ }^{53}$ Thus, this method allows to estimate the probability that the $\mathrm{AD}$ is the cause of dementia through the following rule: low (CERAD = $0-A$ and Braak = 1-2), medium (CERAD B and Braak 3-4); or high (CERAD C and Braak 5-6). ${ }^{54}$ 
Table 1. Rules for the pathological diagnosis of AD.

- The NIA criteria for assessing plaques (including diffuse and neuritic plaques) in the neocortex and hippocampus per unit and corrected by age.

- The criteria based on the semi-quantitative evaluation of plaques and neurofibrillary tangle in the neocortex and hippocampus.

- The CERAD criteria using the semi-quantitative neuritic plaques count adjusted by age, which along with the clinical history of dementia is used to set up the probability of $A D$.

- The topographic categorization of neuritic (neurofibrillary) changes, which includes 6 stages: entorhinal (1 and 2), hippocampal (3 and 4), and neocortical (5 and 6).

- The quantitative criteria of the University of Washington, which is a NIA criteria modification.

There are no specific recommendations for the pathological diagnosis of VCI/VD. However, its importance lies in that allows to identify the type of underlying CVD. Additionally, it also allows to identify injuries in cases of non-detectable lesions by current neuroimaging technologies, such as small cystic infarctions, selective neuronal loss, and microinfarcts.

In this context, Jellinger and Atems proposed as a criterion for pathological diagnosis of MVAD the combination of $\mathrm{AD}$ (confirmed by autopsy) with presence of multiple lacunar infarcts or CVI lesions located in the cortex, basal ganglia, thalamus, hippocampus and white matter, with an infarcted cerebral volume of $30-50 \mathrm{ml}$, approximately. ${ }^{2}$

Diagnosis in investigation studies. For the research purposes, the $\mathrm{AD}$ diagnosis requires the evidence of: 1 ) amyloid deposition in the autopsy study, low $\beta$-amyloid concentrations in cerebrospinal fluid (CSF), or $\beta$-amyloid deposition in positron emission tomography; and 2) neuro-degeneration in the autopsy study, high concentrations of phosphorylated Tau in CSF, or pattern of EA atrophy in the cerebral images. ${ }^{55-57}$ However, amyloid and tau biomarkers are not required in usual clinical practice. On the other hand, the diagnosis of VCI/VD is under discussion due to the heterogeneity of the clinical-neuropsychological phenotype produced by several CVI types. The AHA/ASA recommended establishing a clear causal relationship between the occurrence of vascular event and the onset of cognitive impairment, and between both the location and severity of CVI, clinically detected or identified by brain imaging, with the pattern and severity of cognitive impairment. ${ }^{1}$

Diagnostic challenges. The AHA/ASA highlighted that there are several factors that affect diagnostic accuracy. For example, current imaging technologies are unable to detect microscopic infarctions ( $\leq 3 \mathrm{~mm}$ ) and alterations in small vessels such as arteriosclerosis. ${ }^{1}$ Evenly, there are findings in neuroimaging studies that are not pathognomonic of VCI/VD such as microbleeds, ${ }^{58-60}$ white matter degeneration ${ }^{1}$ and hippocampal atrophy, ${ }^{61,62}$ which may also occur in patients with $A D$.

Cognitive phenotypes. Due to the lack of consensus on the diagnostic criteria and the heterogeneous neuropathological characteristic of the MVAD, this entity has not been widely studied. However, establishing a cognitive profile in relation to $\mathrm{AD}$ can be useful for measuring the contribution of CVD/CVI to cognitive impairment and establishing clinical management and therapeutic strategies in patients with MVAD. ${ }^{28,52,63}$

There are studies showing that the cognitive performance of patients with MVAD is lower than that observed in patients with Alzheimer's dementia, ${ }^{64,65}$ particularly in the attention, ${ }^{65}$ memory, ${ }^{66}$ denomination $^{66}$ visuoconstruction ${ }^{65}$ and executive functions. ${ }^{64}$ Similarly, in patients with Alzheimer's dementia, the subgroup that developed cerebral infarction showed a greater involvement of memory, ${ }^{8,66,67}$ language, ${ }^{67}$ denomination, ${ }^{8,66}$ verbal fluency, ${ }^{8}$ and constructive praxis. ${ }^{8,66}$

Therapeutic guidelines. Currently, the treatment is basically symptomatic and preventive. The use of acetylcholinesterase inhibitor drugs such as donepezil, galantamine and rivastigmine and antidemential drugs such as memantine can be used in patients with Alzheimer's dementia and VD. ${ }^{68,69}$

Studies in patients with MVAD have shown a mild improvement, especially in cognition function, with contradictory results in daily living activities and global status, and showing no statistical superiority in the efficacy of either agent. ${ }^{70}$ Considering the potential adverse effects of medication, it is necessary to carefully evaluate its use in these patients. ${ }^{70}$ Memantine, for example, has demonstrated a cognitive effect similar to acetylcholinesterase inhibitors in patients with VD, although with less adverse effects. ${ }^{71,72}$

Although effective blood pressure control seems to decrease the progression rate of WML in hypertensive 
patients, ${ }^{33}$ there is no evidence that adequate control of blood pressure or levels of glucose, cholesterol and triglyceride modify the dementia progression. ${ }^{73,74} \mathrm{We}$ suspect that both the early and continue use of these measures could generate the necessary evidence for its inclusion in the clinical protocols.

A healthy diet includes a greater amount of vegetables, fruits, nuts, soy proteins, grains and fish, as well as lower consumption of red meat. Longitudinal studies have shown that this dietary regimens can decrease both the progression rate of cognitive impairment and the risk of developing $\mathrm{AD} .{ }^{75,76}$ Likewise, regular exercise ( $\geq 30$ minutes for $\geq 3$ times per week) showed to decrease the progression of cognitive symptoms associated with $\mathrm{AD}$ and $\mathrm{VD},{ }^{77}$ improving the independence and maintaining the daily living activities.

Finally, psychological and social support is critical, particularly when the patient is working. This support should also cover the family, who must understand the progressive loss of independence of the patient.

Conclusions. There is a public health need for new studies that address the diagnosis and treatment of
MVAD. Currently, the available medications offer only a modest clinical benefits once a patient has developed MVAD, without any modification of its evolution. In subjects at risk, the antihypertensive therapy and healthy diet should be both recommend and promoted for preventing or slowing the progression of MVAD.

Recommendations. For improving the health outcomes, we recommend thinking in MVAD as probable diagnosis in all demented patients with an atypical presentation of $\mathrm{AD}$ and coexistence of risk factors for CVD/ CVI.

For improving the value of image studies in the diagnosis of dementia, we recommend to assess the concordance between neuroimaging patterns and postmortem findings. ${ }^{2}$ According the current evidence, it is necessary conduct further studies to develop a better understanding of MVAD.

Author contributions. All authors have contributed significantly to the study and are in agreement with the content of the manuscript.

\section{REFERENCES}

1. Gorelick PB, Scuteri A, Black SE, arli C, Greenberg SM, laola C, et al. Vascular Contributions to Cognitive Impairment and Dementia. Stroke. 2011;42(9):2672-713

2. Zekry D, Hauw J-J, Gold G. Mixed dementia: epidemiology, diagnosis, and treatment. J Am Geriatr Soc. 2002;50(8):1431-8.

3. Chui HC, Ramirez-Gomez L. Clinical and imaging features of mixed Alzheimer and vascular pathologies. Alzheimers Res Ther. 2015;7:21.

4. Hanyu $H$. Diagnosis and treatment of mixed dementia. Brain Nerve. 2012;64(9):1047-55.

5. Lim A, Tsuang D, Kukull W, Nochlin D, Leverenz J, McCormick W, et al. Clinico-neuropathological correlation of Alzheimer's disease in a community-based case series. J Am Geriatr Soc. 1999 ;47(5):564-9.

6. Massoud F, Devi G, Stern Y, Lawton A, Goldman JE, Liu Y, et al. A clinicopathological comparison of community-based and clinicbased cohorts of patients with dementia. Arch Neurol. 1999 ;56(11): 1368-73.

7. Neuropathology Group. Medical Research Council Cognitive Function and Aging Study. Pathological correlates of late-onset dementia in a multicentre, community-based population in England and Wales. Neuropathology Group of the Medical Research Council Cognitive Function and Ageing Study (MRC CFAS). Lancet. 2001;357(9251):169-75.

8. Snowdon DA, Greiner LH, Mortimer JA, Riley KP, Greiner PA, Markesbery WR. Brain infarction and the clinical expression of Alzheimer disease. The Nun Study. JAMA. 1997;277(10):813-7.

9. Torre JC. Vascular basis of Alzheimer's pathogenesis. Ann NY Acad Sci. 2002;977(1):196-215.

10. Langa KM, Foster NL, Larson EB. Mixed dementia: emerging concepts and therapeutic implications. JAMA. 2004;292(23):2901-8.

11. Petrovitch H, White LR, Ross GW, Steinhorn SC, Li CY, Masaki KH, et al. Accuracy of clinical criteria for AD in the Honolulu-Asia Aging Study, a population-based study. Neurology. 2001 24;57(2):226-34.

12. White L, Petrovitch H, Hardman J, Nelson J, Davis DG, Ross GW, et al. Cerebrovascular pathology and dementia in autopsied Honolulu-Asia Aging Study participants. Ann N Y Acad Sci. 2002 ;977:9-23.
13. Suemoto CK, Ferretti-Rebustini REL, Rodriguez RD, Leite REP, Soterio L, Brucki SMD, et al. Neuropathological diagnoses and clinical correlates in older adults in Brazil: A cross-sectional study. PLOS Med. 2017;14(3):e1002267.

14. Matsui Y, Tanizaki Y, Arima H, Yonemoto K, Doi Y, Ninomiya T, et al. Incidence and survival of dementia in a general population of Japanese elderly: the Hisayama study. J Neurol Neurosurg Psychiatr. 2009; 80(4):366-70.

15. Troncoso JC, Zonderman AB, Resnick SM, Crain B, Pletnikova O, O'Brien RJ. Effect of infarcts on dementia in the Baltimore longitudinal study of aging. Ann Neurol. 2008;64(2):168-76.

16. Brayne C, Richardson K, Matthews FE, Fleming J, Hunter S, Xuereb $\mathrm{JH}$, et al. Neuropathological correlates of dementia in over-80-year-old brain donors from the population-based Cambridge city over-75s cohort (CC75C) study. J Alzheimers Dis. 2009;18(3):645-58.

17. Schneider JA, Aggarwal NT, Barnes L, Boyle P, Bennett DA. The Neuropathology of Older Persons with and With Dementia from Community versus Clinic Cohorts. J Alzheimers Dis. 2009;18(3):691-701.

18. Meguro K, Ishii H, Yamaguchi S, Ishizaki J, Shimada M, Sato M, et al. Prevalence of dementia and dementing diseases in Japan: the Tajiri project. Arch Neurol. 2002;59(7):1109-14.

19. Snowdon DA, Greiner LH, Mortimer JA, Riley KP, Greiner PA, Markesbery WR. Brain infarction and the clinical expression of Alzheimer disease. The Nun Study. JAMA. 1997;277(10):813-7.

20. Petrovitch H, Ross GW, Steinhorn SC, Abbott RD, Markesbery W, Davis $\mathrm{D}$, et al. AD lesions and infarcts in demented and non-demented Japanese-American men. Ann Neurol. 2005;57(1):98-103.

21. Jack CR, Knopman DS, Jagust WJ, Petersen RC, Weiner MW, Aisen PS, et al. Update on hypothetical model of Alzheimer's disease biomarkers. Lancet Neurol. 2013;12(2):207-16.

22. Villemagne VL, Burnham S, Bourgeat P, Brown B, Ellis KA, Salvado O, et al. Amyloid $\beta$ deposition, neurodegeneration, and cognitive line in sporadic Alzheimer's disease: a prospective cohort study. Lancet Neurol. 2013;12(4):357-67. 
23. Mehlig K, Skoog I, Waern M, Miao Jonasson J, Lapidus L, Björkelund C, et al. Physical activity, weight status, diabetes and dementia: a 34-year follow-up of the population study of women in Gothenburg. Neuroepidemiology. 2014;42(4):252-9.

24. de Bruijn RF, Ikram MA. Cardiovascular risk factors and future risk of Alzheimer's disease. BMC Med. 2014; https://doi.org/10.1186/ s12916-014-0130-5

25. Zhao Y, Gong C-X. From chronic cerebral hypoperfusion to Alzheimerlike brain pathology and neurodegeneration. Cell Mol Neurobiol. 2015;35(1):101-10.

26. Iaola C. Hypertension and Dementia. Hypertension. 2014;64(1):3-5

27. O'Brien JT, Thomas A. Vascular dementia. Lancet. 2015;386(10004): 1698-706.

28. Chui HC, Brown NN. Vascular cognitive impairment. CONTINUUM: Lifelong Learning in Neurology. 2007;13:109-43.

29. Torre JC de la. Alzheimer Disease as a Vascular Disorder: Nosological Evidence. Stroke. 2002;33(4):1152-62.

30. Snyder HM, Corriveau RA, Craft S, Faber JE, Greenberg S, Knopman D, et al. Vascular Contributions to Cognitive Impairment and Dementia Including Alzheimer's Disease. Alzheimers Dement. 2015 ;1(6):710-7.

31. Breteler MM, van den Ouweland FA, Grobbee DE, Hofman A. A community-based study of dementia: the Rotterdam Elderly Study. Neuroepidemiology. 1992;11 Suppl 1:23-8.

32. Launer LJ, Ross GW, Petrovitch H, Masaki K, Foley D, White LR, et al. Midlife blood pressure and dementia: the Honolulu-Asia aging study. Neurobiol Aging. 2000;21(1):49-55

33. Skoog I, Lernfelt B, Landahl S, Palmertz B, Andreasson LA, Nilsson L, et al. 15-year longitudinal study of blood pressure and dementia. Lancet. 1996;347(9009):1141-5

34. Morris MS, Jacques PF, Rosenberg $\Perp H$, Selhub J, National Health and Nutrition Examination Survey. Hyperhomocysteinemia associated with poor recall in the third National Health and Nutrition Examination Survey. Am J Clin Nutr. 2001;73(5):927-33.

35. Duron E, Hanon O. Vascular risk factors, cognitve line, and dementia. Vasc Health Risk Manag. 2008;4(2):363-81.

36. Doddy RS, Massman PJ, Mawad M, Nance M. Cognitive consequences of subcortical magnetic resonance imaging changes in Alzheimer's disease: comparison to small vessel ischemic vascular dementia. Neuropsychiatry Neuropsychol Behav Neurol. 1998;11(4):191-9.

37. Modrego PJ, Rios C, Pérez Trullen JM, Errea JM, García-Gómara MJ, Sanchez S. The cerebrovascular pathology in Alzheimer's disease and its influence on clinical variables. Am J Alzheimers Dis Other Demen. 2008;23(1):91-6.

38. Jack CR, Knopman DS, Jagust WJ, Petersen RC, Weiner MW, Aisen PS, et al. Update on hypothetical model of Alzheimer's disease biomarkers. Lancet Neurol. $2013 ; 12(2): 207-16$

39. Vlassenko AG, Benzinger TL, Morris JC. PET Amyloid-Beta Imaging in Preclinical Alzheimer's Disease. Biochim Biophys Acta. 2012;1822(3): 370-9.

40. Okamura N, Furumoto S, Fodero-Tavoletti MT, Mulligan RS, Harada $R$, Yates $P$, et al. Non-invasive assessment of Alzheimer's disease neurofibrillary pathology using 18F-THK5105 PET. Brain. 2014;137(Pt 6):1762-71.

41. Dickerson BC, Wolk DA. MRI cortical thickness biomarker predicts AD-like CSF and cognitive line in normal adults. Neurology. 2012;78(2): 84-90.

42. Tondelli M, Wilcock GK, Nichelli P, De Jager CA, Jenkinson M, Zamboni G. Structural MRI changes detectable up to ten years before clinical Alzheimer's disease. Neurobiol Aging. 2012;33(4):825.e25-36.

43. Chui HC, Victoroff JI, Margolin D, Jagust W, Shankle R, Katzman R. Criteria for the diagnosis of ischemic vascular dementia proposed by the State of California Alzheimer's Disease Diagnostic and Treatment Centers. Neurology. 1992;42(3 Pt 1):473-80.

44. Román GC, Tatemichi TK, Erkintti T, Cummings JL, Masdeu JC, Garcia $\mathrm{JH}$, et al. Vascular dementia: diagnostic criteria for research studies. Report of the NINDS-AIREN International Workshop. Neurology. 1993; 43(2):250-60.

45. Morris JC, Heyman A, Mohs RC, Hughes JP, van Belle G, Fillenbaum $\mathrm{G}$, et al. The Consortium to Establish a Registry for Alzheimer's Disease (CERAD). Part I. Clinical and neuropsychological assessment of Alzheimer's disease. Neurology. 1989;39(9):1159-65.

46. Looi JC, Sachdev PS. Differentiation of vascular dementia from AD on neuropsychological tests. Neurology. 1999;53(4):670-8.
47. Sachdev P, Kalaria R, O’Brien J, Skoog I, Alladi S, Black SE, et al. Diagnostic criteria for vascular cognitive disorders: a VASCOG statement. Alzheimer Dis Assoc Disord. 2014;28(3):206-18.

48. Snowdon DA, Greiner LH, Mortimer JA, Riley KP, Greiner PA, Markesbery WR. Brain infarction and the clinical expression of Alzheimer disease. The Nun Study. JAMA. 1997;277(10):813-7.

49. Skoog I. Vascular aspects in Alzheimer's disease. J Neural Transm Suppl. 2000;59:37-43

50. Tullberg M, Fletcher E, arli C, Mungas D, Reed BR, Harvey DJ, et al. White matter lesions impair frontal lobe function regardless of their location. Neurology. 2004;63(2):246-53.

51. Brown WR, Moody DM, Thore CR, Challa VR, Anstrom JA. Vascular dementia in leukoaraiosis be a consequence of capillary loss not only in the lesions, but in normal-appearing white matter and cortex as well. J Neurol Sci. 2007;257(1-2):62-6.

52. Jellinger KA, Attems J. Neuropathological evaluation of mixed dementia. J Neurol Sci. 2007;257(1-2):80-7

53. Braak H, Braak E. Neuropathological stageing of Alzheimer-related changes. Acta Neuropathol. 1991;82(4):239-59.

54. Hyman BT, Troowski JQ. Consensus recommendations for the postmortem diagnosis of Alzheimer disease from the National Institute on Aging and the Reagan Institute Working Group on diagnostic criteria for the neuropathological assessment of Alzheimer disease. J Neuropathol Exp Neurol. 1997;56(10):1095-7.

55. Sperling RA, Aisen PS, Beckett LA, Bennett DA, Craft S, Fagan AM, et al. Toward defining the preclinical stages of Alzheimer's disease: Recommendations from the National Institute on Aging-Alzheimer's Association workgroups on diagnostic guidelines for Alzheimer's disease. Alzheimers Dement. 2011;7(3):280-92.

56. Albert MS, DeKosky ST, Dickson D, Dubois B, Feldman HH, Fox NC et al. The diagnosis of mild cognitive impairment due to Alzheimer's disease: Recommendations from the National Institute on AgingAlzheimer's Association workgroups on diagnostic guidelines for Alzheimer's disease. Alzheimers Dement. 2011;7(3):270-9.

57. Jack CR, Albert M, Knopman DS, McKhann GM, Sperling RA, Carillo $M$, et al. Introduction to Revised Criteria for the Diagnosis of Alzheimer's Disease: National Institute on Aging and the Alzheimer Association Work groups. Alzheimers Dement. 2011;7(3):257-62.

58. Kirsch W, McAuley G, Holshouser B, Petersen F, Ayaz M, Vinters HV et al. Serial susceptibility weighted MRI measures brain iron and microbleeds in dementia. J Alzheimers Dis. 2009;17(3):599-609.

59. Cordonnier C, van der Flier WM, Sluimer JD, Leys D, Barkhof F, Scheltens P. Prevalence and severity of microbleeds in a memory clinic setting Neurology. 2006;66(9):1356-60.

60. Lee DY, Fletcher E, Martinez O, Ortega M, Zozulya N, Kim J, et al. Regional pattern of white matter microstructural changes in norma aging, $\mathrm{MCl}$, and AD. Neurology. 2009;73(21):1722-8.

61. Jagust WJ, Zheng L, Harvey DJ, Mack WJ, Vinters HV, Weiner MW, et al. Neuropathological Basis of Magnetic Resonance Images in Aging and Dementia. Ann Neurol. 2008;63(1):72-80

62. Zarow C, Sitzer TE, Chui HC. Understanding hippocampal sclerosis in the elderly: epidemiology, characterization, and diagnostic issues. Curr Neurol Neurosci Rep. 2008;8(5):363-70.

63. Jellinger KA. The enigma of mixed dementia. Alzheimers Dement. 2007; 3(1):40-53.

64. Reed BR, Mungas DM, Kramer JH, Ellis W, Vinters HV, Zarow C, et al. Profiles of neuropsychological impairment in autopsy-defined Alzheimer's disease and cerebrovascular disease. Brain. 2007;130(Pt 3):731-9.

65. Dong Y, Gan DZQ, Tay SZ, Koay WI, Collinson SL, Hilal S, et al. Patterns of neuropsychological impairment in Alzheimer's disease and mixed dementia. J Neurol Sci. 2013;333(1-2):5-8.

66. Bowler JV, Eliasziw M, Steenhuis R, Munoz DG, Fry R, Merskey H, et al. Comparative evolution of Alzheimer disease, vascular dementia, and mixed dementia. Arch Neurol. 1997;54(6):697-703.

67. Song I-U, Kim J-S, Kim Y-I, Eah K-Y, Lee K-S. Clinical Significance of Silent Cerebral Infarctions in Patients With Alzheimer Disease. Cogn Behav Neurol. 2007;20(2):93-98

68. Román GC, Salloway S, Black SE, Royall DR, arli C, Weiner MW, et al Randomized, placebo-controlled, clinical trial of donepezil in vascular dementia: differential effects by hippocampal size. Stroke. 2010; 41(6): 1213-21.

69. Auchus AP, Brashear HR, Salloway S, Korczyn AD, De Deyn PP, Gassmanner C, et al. Galantamine treatment of vascular dementia: a randomized trial. Neurology. 2007;69(5):448-58. 
70. Ballard C, Sauter M, Scheltens P, He Y, Barkhof F, van Straaten ECW, et al. Efficacy, safety and tolerability of rivastigmine capsules in patients with probable vascular dementia: the VantagE study. Curr Med Res Opin. 2008;24(9):2561-74.

71. National Institute for Health and Care Excellence. Dementia: supporting people with dementia and their carers in health and social care. 2016 [cited 2017 12]. Available from: https://www.nice.org.uk/guidance/cg42

72. Wilcock G, Möbius HJ, Stöffler A, MMM 500 group. A double-blind, placebo-controlled multicentre study of memantine in mild to moderate vascular dementia (MMM500). Int Clin Psychopharmacol. 2002;17(6): 297-305.

73. Orgogozo J-M, Rigaud A-S, Stöffler A, Möbius H-J, Forette F. Efficacy and safety of memantine in patients with mild to moderate vascular dementia: a randomized, placebo-controlled trial (MMM 300). Stroke. 2002;33(7):1834-9.
74. Pearce LA, McClure LA, Anderson DC, Jacova C, Sharma M, Hart RG, et al. Effects of long-term blood pressure lowering and dual antiplatelet therapy on cognition in patients with recent lacunar stroke: Secondary Prevention of Small Subcortical Strokes (SPS3) trial The SPS3 Investigators. Lancet Neurol. 2014;13(12):1177-85.

75. Ngandu T, Lehtisalo J, Solomon A, Levälahti E, Ahtiluoto S, Antikainen $\mathrm{R}$, et al. A 2 year multidomain intervention of diet, exercise, cognitive training, and vascular risk monitoring versus control to prevent cognitive line in at-risk elderly people (FINGER): a randomised controlled trial. Lancet. 2015;385(9984):2255-63.

76. Lourida I, Soni M, Thompson-Coon J, Purandare N, Lang IA, Ukoumunne OC, et al. Mediterranean diet, cognitive function, and dementia: a systematic review. Epidemiology. 2013;24(4):479-89.

77. Safouris A, Tsivgoulis G, Sergentanis TN, Psaltopoulou T. Mediterranean Diet and Risk of Dementia. Curr Alzheimer Res. 2015;12(8):736-44. 